\title{
Performance Enhancement of Radial Distribution System via Network Reconfiguration: A Case Study of Urban City in Nepal
}

\author{
Govinda P.Pandey ${ }^{\circledR}$, Bijen Mali2 ${ }^{2}$ Ashish Shrestha ${ }^{3}$, Ajay Singh4, Ajay K. Jha1 \\ IInstitute of Engineering, Pulchowk Campus, Tribhuvan University, Patan 44700, Nepal \\ 2NEA Engineering Company Limited, Kathmandu 44600, Nepal \\ ${ }^{3}$ Department of Electrical Engineering, Information Technology and Cybernetics, University of South-Eastern \\ Norway, Porsgrunn N-3918, Norway \\ ${ }^{4}$ Department of Electrical Engineering, Khwopa College of Engineering, Bhaktapur 44800, Nepal \\ ${ }^{\otimes}$ Corresponding Author: govinda.link@gmail.com | Phone: +977-9846362525
}

\begin{abstract}
Received : January 11, $2021 \quad$ Revision : January 27, $2021 \quad$ Accepted : February 17, 2021
Abstract

Increasing unplanned energy demand has led to network congestion, increased power losses and poor voltage profile. To decrease these adverse effects of an unmanaged power system, distribution network reconfiguration provides an effective solution. This paper deals with improving the power losses and poor voltage profile of the Phulchowk Distribution and Consumer Services (DCS) via the implementation of an optimum reconfiguration approach using Genetic Algorithm (GA). The developed algorithm is firstly put into work on the IEEE 33 bus system to improve its voltage profile and the poor power losses. The effectiveness of the developed system is validated as it reduced the voltage drop by $5.66 \%$ and the power loss by $25.96 \%$. The algorithm is further implemented on Pulchowk DCS. Without overhauling the entire network, a better reconfiguration of the present network is provided which can be realized with the reconfiguration or allocation of tie-switches and sectionalizing switches within the network. After reconfiguring the system in different individual cases, optimum network reconfiguration is selected that improved the voltage profile and the active and reactive power losses when compared to the base case scenario.
\end{abstract}

Keywords: Radial Distribution System; Grid Reconfiguration; Power System; Genetic Algorithm.

\section{Introduction}

In Nepal, the combined transmission and distribution loss is $15.32 \%$ of total available electricity within the country, where distribution losses contribute to around $11.28 \%$ or $(73.63 \%$ of the combined transmission and distribution loss) (NEA, 2019). In the power system, around 5 to $13 \%$ of the total generated power was estimated to be wasted in the form of I2R losses at the distribution level (Al-Abri, 2012). The energy generation alone has increased by $9.92 \%$ within the last year (NEA, 2019). With the 66kV transmission line already in place for the power supply in Kathmandu valley, the upgradation of the existing distribution system is due for a major overhaul. Also, the most adopted radial type distribution system suffers from unstable voltage and power losses problem (Prakash, Lallu, Islam, \& Mamun, 2016). To reduce the stated losses and address the problems related to system stability, different techniques can be applied. Feeder restructuring, capacitor placement, distributed generation placement, network reconfiguration and installation of smart metering are few techniques that have been implemented to reduce the power losses in the distribution system (L.Ramesh, 2011; Shilpa Kalambe, 2013; Y. Al-Mahroqi, 2012).The network reconfiguration method is one such method that is proven to be effective and reliable (Napis, Khatib, Hassan, \& Sulaima, 2018). The distribution network reconfiguration and re-settlement is a complex combinational work that contains the optimization process; aimed at finding a radial operating structure and minimizes the system power loss while satisfying operating constraints (Flaih et al., 2017; Rao, Ravindra, Satish, \& Narasimham, 2012). With the advent of highly capable computers,a requirement of high computing power and complex decision-making process (Shilpa Kalambe, 2013) for network reconfiguration can now be easily fulfilled. Optimum reconfiguration scheme of the network for the minimization of distribution system losses can be achieved using various forms of algorithms such as GA, particle swarm optimization, mixed integer programming(Shanghua Guo, 2020) and grey wolf optimization(A. V. Sudhakara Reddy, 2017; Ayodeji Olalekan Salau, 2020; Wardiah Mohd Dahalan, 2012).

The successful planning for integration of switches in radial feeder reconfiguration of distribution systems must be covered by all of the static and dynamic analysis on technical and economic aspects(Badran, Mekhilef, Mokhlis, \& Dahalan, 2017; Georgilakis \& Hatziargyriou, 2015; Shrestha, 2017). Configuration should be conducted to obtain minimum loss under a given constraint of technical, environmental and economic aspects(Basiago, 1998; Shrestha, Jha, Shah, \& Gautam, 2016; Shrestha, Shah, Gautam, \& Jha, 2017). However, there is still a research gap for optimal reconfigurations by proper arrangement of the existing structure for a distribution network with multi feeder radial line. It can be implemented/ conducted through sectionalizing and tie-switching for the operation in optimized modules. This method can be used in planning purposes for re-configurations that help to improve the overall voltage profile of the 
system and minimize the distribution power losses(Shrestha et al., 2019).

In this study, the authors present the possibility of enhancing the performance of existing distribution networks by implementing the concept of network reconfiguration. To achieve this, a GA-based model has been developed that provides an optimized method of system reconfiguration: an optimized reconfigured network. This study first introduces the issues and importance of distribution systems in power system engineering in section 1 . Section 2 presents an overview of the current status of the Nepalese distribution network (i.e. case study). Section 3 focuses on the adopted methodology to complete this research work. The obtained results with detailed explanations are presented in section 4. Finally, in section 5, conclusions are drawn and presented based on the existing constraints. Even though it is explained in detail in the following chapters, the novelty and the major contribution of this paper are related to:

a) Development of a solution to improve the distribution system through the use of network reconfiguration to carter the unplanned growth of energy demand.

b) Comparison between all the possible causes of distribution reconfiguration to present an optimum case of a network that minimizes the voltage drop and power loss of the system.

\section{Current Scenario of the Case Study Area}

The case study is conducted on Pulchowk Distribution and Consumer Services (DCS), being operated by Nepal Electricity Authority (NEA), located at $\left(27^{\circ} 40^{\prime} 40.26^{\prime}\right.$ 'N, $85^{\circ} 18^{\prime} 57.48^{\prime}$ 'E). Pulchowk is an urban city of Lalitpur, Nepal. It has a radial type distribution system with nine feeders at $11 \mathrm{kV}$ voltage level and 142 buses in total. The total length of the network is estimated to be around $65.17 \mathrm{~km}$. The Geographic Information System (GIS) view of the distribution network is shown in Figure 1. the area consists of a distribution line having different radial feeders, which can be interconnected or re-configured by allocating tie-switches (normally open) and sectionalizing switches (normally closed) in the existing system. Details of the feeders are listed in Table 1. Here, the total active and reactive loads of the system are calculated to be 14,132 $\mathrm{kW}$ and 10,599 kVAR respectively. The maximum active load of $200 \mathrm{~kW}$ is observed at buses $10,17,95,100,109$ and 127 and a maximum reactive load of $150 \mathrm{kVAR}$ is observed at bus 30 . In Nepal, the loss in the distribution system is significantly high (i.e. 11.28\%), which occurs in the case area $8.5 \%$ (Monthly loss report of Pulchowk Distribution and Consumer Services, 2019). Although there have been certain efforts being taken by the NEA, the losses through decreasing, are still prevalent.

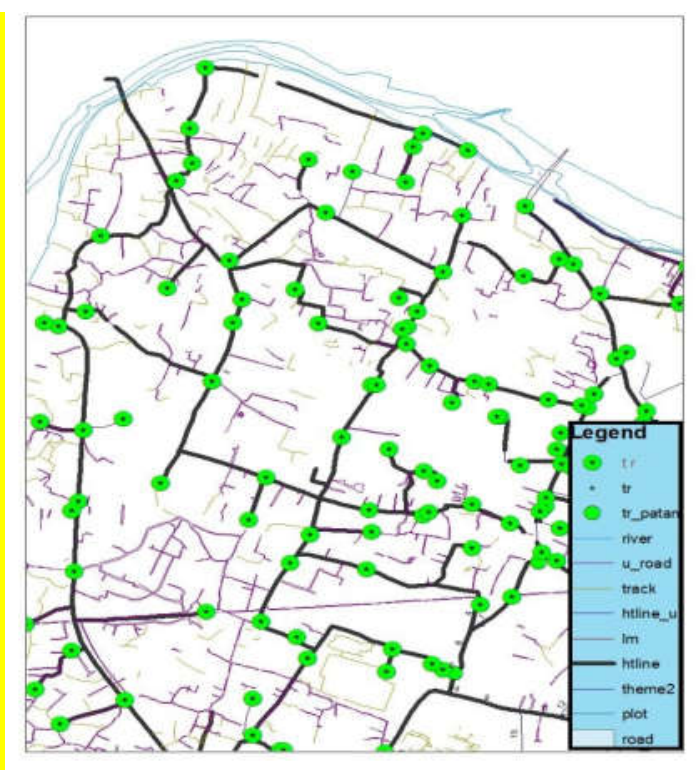

Figure 1: GIS view showing the distribution line and load centre of Pulchowk DCS network

Table 1.Pulchowk DCS feeder represented with bus

\begin{tabular}{ccccc}
\hline Feeder Name & $\begin{array}{c}\text { Feeder } \\
\text { Number }\end{array}$ & $\begin{array}{c}\text { Total Number of } \\
\text { Bus Included }\end{array}$ & $\begin{array}{c}\text { Feeder Start Bus } \\
\text { Number }\end{array}$ & $\begin{array}{c}\text { Feeder End Bus } \\
\text { Number }\end{array}$ \\
\hline Patan - Jawalakhel & 1 & 4 & 1 & 4 \\
Patan - Mangalbazar & 2 & 15 & 5 & 20 \\
Patan - Pulchowk & 3 & 17 & 21 & 38 \\
Patan - Pharping & 4 & 12 & 39 & 51 \\
Patan - Ringroad & 5 & 9 & 52 & 70 \\
Patan - Sainbu & 6 & 16 & 61 & 98 \\
Teku - Pulchowk & 7 & 20 & 78 & 124 \\
Thapathali - Patan & 8 & 25 & 99 & 142 \\
Thapathali - Sanepa & 9 & 18 & 124 & \\
\hline
\end{tabular}




\section{Materials \&Methods}

The methodology implemented in this study includes a literature survey and data collection, mathematical modeling and algorithm selection, execution of the techniques in mathematical form and result validation. The processes and important steps of the adopted methodology are discussed below:

\section{A. Literature Survey and Data Collection}

This study commences with the literature survey and data collection. In the preliminary stage, a literature review and study of the work to be done on the case area are performed to get an understanding of the technology being demonstrated. Data collection involves the collection of primary and secondary data. Site visits and data from the GIS map are taken as the source of primary data for this study. The source for the secondary data includes information adaptation from previous similar works on the distribution system and related published articles. Published articles, governmental reports, organizational data were referred to develop the concept of technical aspects.

\section{B. Mathematical Modelling and Algorithm Selection}

Mathematical modeling is the process of converting real-world problems into mathematical formulations whose theoretical and numerical analysis will be used for insight, answers, and guidance to tackle the original problem.

The fitness function of the proposed methodology is to minimize the total active power loss under given constraints and conditions. The objective function is the sum of total losses of the Radial Distribution System (RDS) and is given in Equation 1. The power loss $\left(P_{\text {loss }}\right)$ of the branch is evaluated from branch current $(\mathrm{I})$ and branch resistance $(\mathrm{R})$ as $P_{\text {loss }}=I^{2} R$.

$$
\text { Fitness function }=\sum_{i=1}^{\text {total }} P_{i, \text { loss }}
$$

The fitness function is evaluated for each particle of the population and after the initialization of Personal best $\left(P_{\text {best }}\right)$ and Global best $\left(\mathrm{G}_{\text {best }}\right)$, the position and velocity of a particle are updated using Equations 2 and 3, which is then $P_{\text {best }}$ and $\mathrm{G}_{\text {best }}$ are updated.

$$
\begin{aligned}
& v_{i d}=w \times v_{i d}+c_{1} * \operatorname{rand}() *\left(p_{i d}-x_{i d}\right)+c_{2} * \operatorname{rand}() *\left(p_{g d}-x_{i d}\right) \\
& x_{i d}=\left(x_{i d}+v_{i d}\right) \\
& P_{k}=P^{\prime}{ }_{k+1}+r_{k} \frac{\left({P^{\prime}}^{2}{ }_{k+1}+{Q^{\prime}}^{2}{ }_{k+1}\right)}{V^{2}{ }_{k+1}} \\
& P^{\prime}{ }_{k+1}=P_{k+1}+P_{L k+1} \\
& Q^{\prime}{ }_{k+1}=Q_{k+1}+Q_{L k+1}
\end{aligned}
$$

Where, $P_{k+1}$ and $Q_{k+1}$ are the effective real and reactive power flows from node ' $\mathrm{k}+1^{\prime}$ and $P_{L k+1}$ and $Q_{L k+1}$ are loads that are connected at node ' $k+1$ '.

$$
V_{k+1}=V_{k}-Z_{k} I_{k}
$$
' $\mathrm{k}+1$ '.

Here, $I_{k}$ is the current flow through the branch and $\mathrm{Zk}$ is the impedance of the branch connected from node ' $\mathrm{k}$ ' to node

With the required mathematical modeling in place, the discussed mathematical model is then used to develop the algorithm. The technical analysis performed for RDS insights into the weakness and strengths of the system with power losses and bus voltage of each bus, and hence the integration planning process becomes decisive for the outcomes. Figure 2 presents the flow chart to identify the base case power loss and system loss computation.

The proposed methodology starts with the input of line data and bus data of the RDS. The voltage of each bus of the network is set to $1.00 \mathrm{pu}$ and then the branch currents are calculated by backward sweep propagation using equations 4 and 5. The magnitude of voltage and phase angle is updated using equation 6 in forwarding sweep propagation. These two steps of backward and forward sweep propagation are iteratively continued until the convergence criteria are met. To avoid an infinite loop condition, the maximum number of possible iterations is set to 100 . The updated voltages and currents with the computed power losses are taken for base condition values for the RDS network without reconfiguration. The computed power losses and voltage level are finally saved as a base condition in the Base.txt file. With the base condition of the system obtained, the next step is to reconfigure the distribution system to improve the voltage of the system with minimum power losses, and this is done in the following set of steps.

Step 1: Forecast possible tie-switches allocation to be closed.

Step 2: Forecast possible switches to be opened.

Step 3: Find available tie-lines allocation to remove shadow (tie-line with only one end connected to one of the shadow nodes).

Step 4: Select the first available tie-line.

Step 5: Prepare modified line data connecting the selected tie-line.

Step 6: Conduct load flow using the backward/forward sweep method for the prepared module. 


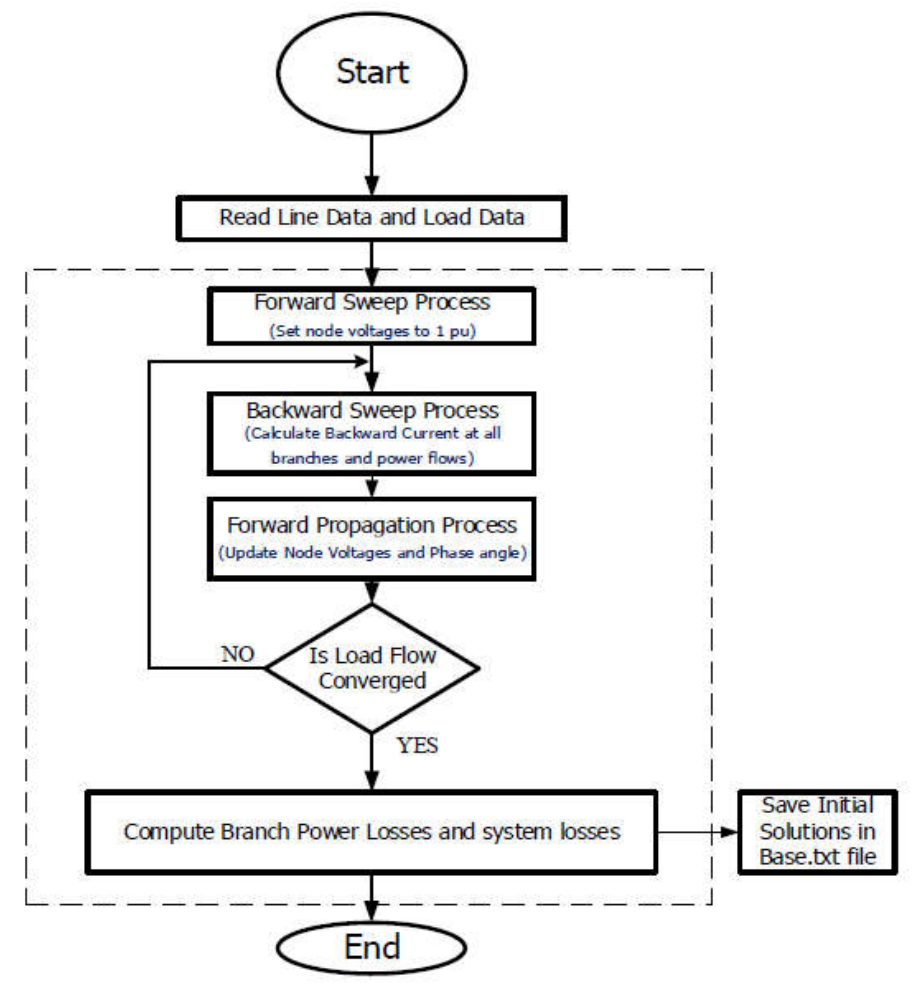

Figure 2: Flow chart of base case power loss and system loss computation

\section{Overall System Development}

After the selection and development of mathematical modeling and algorithm, the two are implemented for simulation in MATLAB. First, all of the system inputs are taken and entered into the developed model in MATLAB, for the numerous operating cases, and then the optimum configurations are evaluated using corresponding models. The implementation of the mathematical modeling and algorithms is achieved in MATLAB with the adoption of a simulation flowchart as shown in Figure 3. Figure 3 presents the complete methodology for the analysis and planning of reconfiguration in the radial distribution system. The technical analysis performed for RDS insights into the weakness and strengths of the system with power losses in each bus and the voltage of specified buses. Hence, the integration planning process becomes decisive for the outcomes.

There are normally two types of switches used in network reconfiguration: (a) sectionalizing switches (normally closed) and (b) tie switches (normally open). This process starts with the computation of the base case's power loss and the system voltage profile, then the process detects all the switching (sectionalizing switches and tie-switches) points for the said RDS. N-sized vector is formed based on all the possible combinations of switches to reconfigure the system with different options of the radial feeders. Based on each possible scenario, the line data and load data are read. Furthermore, the backward/ forward sweep algorithm is applied for each of these cases to calculate the branch power losses and system losses. The obtained results are saved in the form of iteration No.txt file during each iteration. The whole iteration process is carried out and repeated for $\mathrm{N}$ number of times.

With the base case and possible reconfiguration noted and calculations performed, the data of $\mathrm{N}$ set for switching point vectors of different reconfiguration feeders are saved. And with the completion of calculations for all of the $\mathrm{N}$ possible scenarios, the set reconfiguration solutions, the Iteration_No.txt files, are compared with the Base.txt file. And finally based on the calculated value of losses and voltage profile, the possible scenarios for the reconfiguration of the system are comparatively ranked and then the optimized solution having the least losses from the $\mathrm{N}$ possible solutions is selected as the optimum solution for the network reconfiguration. The detailed flow chart for the ranking of the reconfigured system based on the loss reduction is shown in Figure 4.

Here, the main aim is to prepare multiple sets of modules based on various possible network reconfigurations. These reconfigurations are achieved through the specialization of various parts of the network and/ or changing the state of tie-switches. Firstly, a forecast of possible tie-switches to be closed (for network reconfiguration) and possible switches to be opened (for specialization) is conducted. Available tie-lines allocation to remove the shadow is then found. The first available tie-line is then selected. With the network reconfigured, the modified line data are noted and finally load flow is carried out using backward/ forward sweep methods. Multiple individual cases are prepared using this method. With the multiple results of modified network reconfigurations obtained, it can be easily cross-checked with the base model for comparison. The optimum network reconfiguration which provides the best voltage profile and minimum loss is then identified. The enhanced module is recommended for the most sensitive system which provides the minimum power losses under requested voltage limits. The arrangement of the set-switching is selected based on the topological location of each bus with possible location and fix the switching position between the separate feeders. The tapping of 
the line is done between the different feeders through a dog conductor.

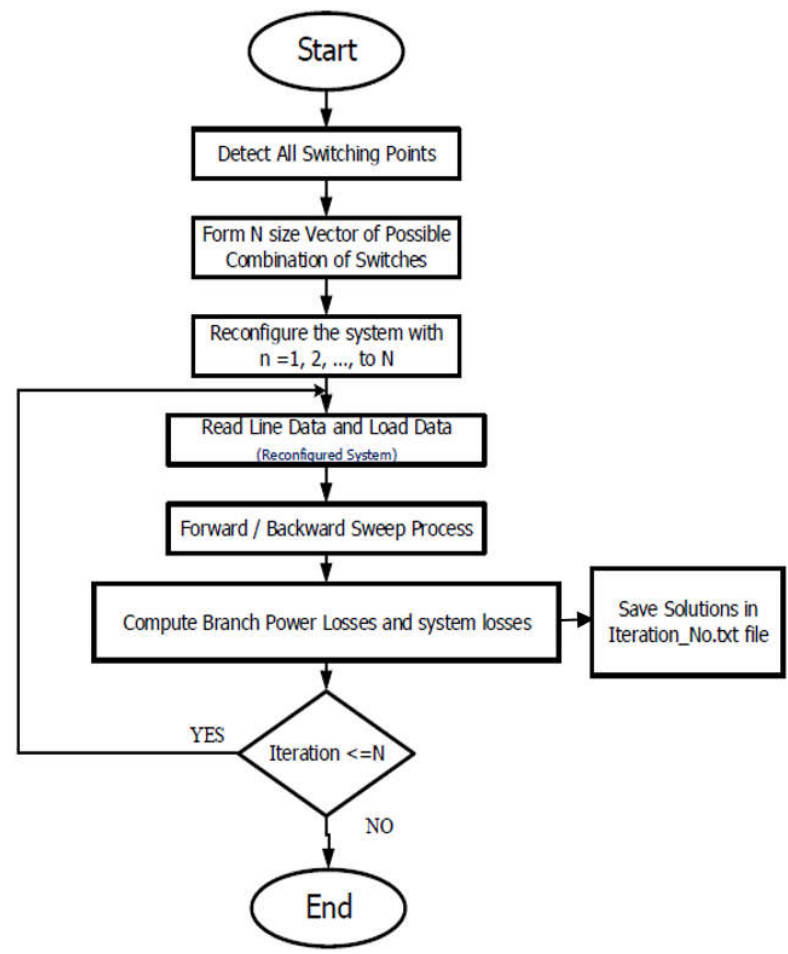

Figure 3: Load flow chart for different configuration power losses and system losses computation

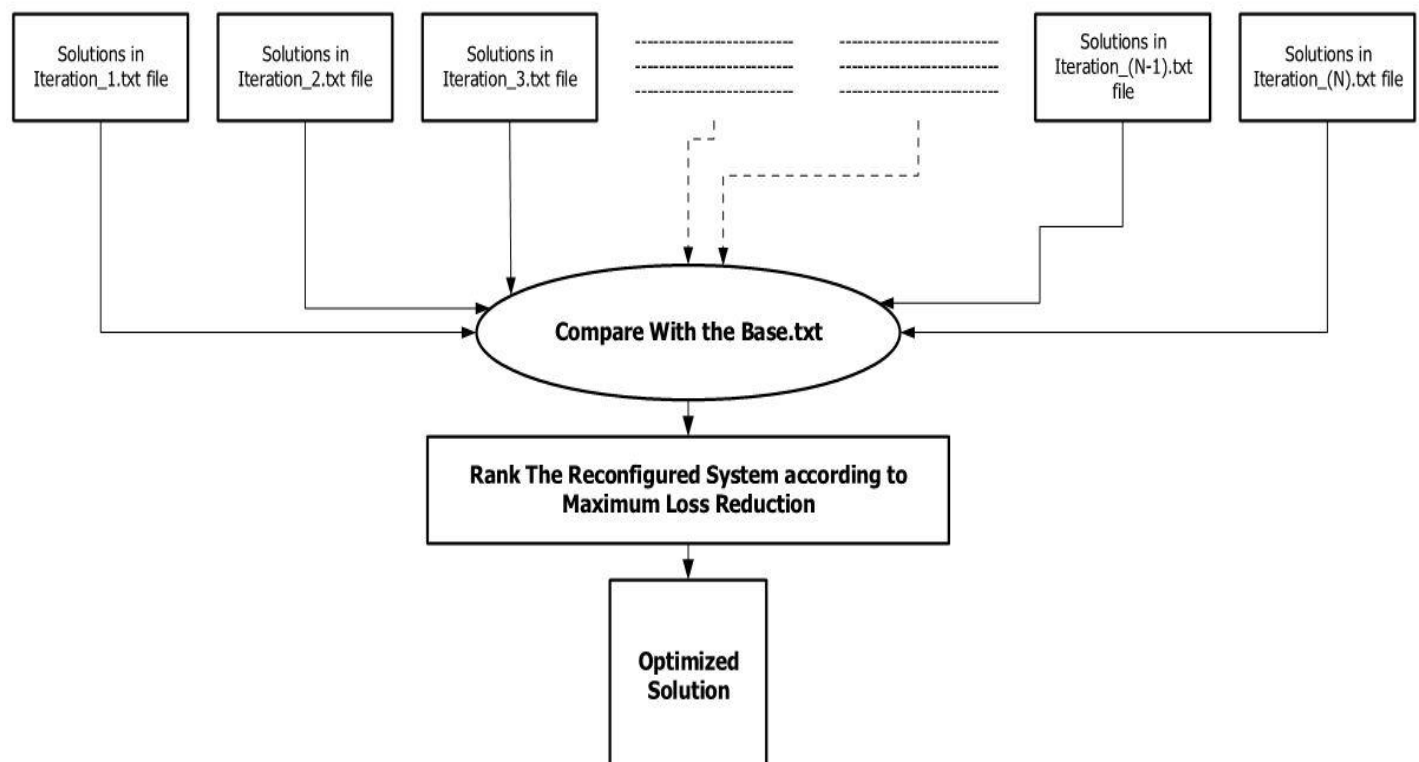

Figure 4: Flow chart for ranking the reconfigured system according to maximum loss reduction

\section{Results and Discussion}

\section{A. IEEE 33 Bus System}

Before the optimum solution for the case scenario is calculated using the developed solution, the reliability of the developed solution is put into test by running the developed algorithm to obtain the optimum reconfiguration of the IEEE 33 bus system. The IEEE 33 bus system comprises 33 buses with 32 lines. The first bus (Bus number 1) in the system is taken as the substation which supplies power to all of the buses connected with fixed loads. This is depicted in Figure 5. Being a radial network, configurations are carried out by manipulating the tie switches and sectionalizing switches in the feeder system. The distribution networks are built as interconnected networks, and while in operation they are arranged into a radial tree-like structure. The distribution systems are divided into subsystems of radial feeders, which contain several normally closed switches and normally open switches. In this system, Bus 1 is taken as the reference bus with $1 \mathrm{pu}$ bus voltage. The total active and reactive loads of the system are calculated to be 3,715 $\mathrm{kW}$ and 2,300 $\mathrm{kW}$ respectively. With the base case, the tie lines (which are represented using the dotted lines) are left open. After that, the 
calculations are conducted and the base scenario is saved. Then, the calculations for 15 cases are conducted for optimization purpose. The possible tie-line connections are stated in Table 2.

Table 2: IEEE 33 bus of different possible condition

\begin{tabular}{cccc}
\hline Test case & Tie-line connected & Test case & Tie-line connected \\
\hline Base case & No any & 8 & $37-33$ \\
1 & 34 & 9 & $37-35$ \\
2 & 37 & 10 & $33-35$ \\
3 & 33 & 11 & $34-37-33$ \\
4 & 35 & 12 & $34-37-35$ \\
5 & $34-37$ & 13 & $37-33-35$ \\
6 & $34-33$ & 14 & $33-35-34$ \\
7 & $34-35$ & 15 & $34-37-33-35$ \\
\hline
\end{tabular}

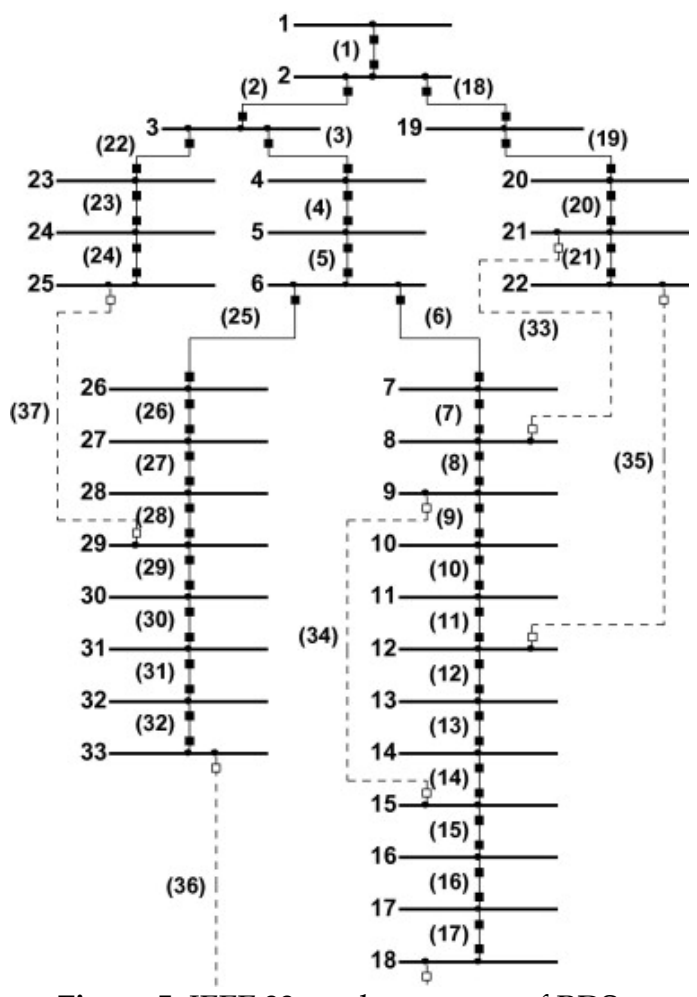

Figure 5: IEEE 33 test bus system of RDS

The developed GA is then used in these possible cases to figure out the optimum solution for the IEEE 32 system. Among the 15 possible reconfigurations for the IEEE 33 bus system, case 13 demonstrates the best overall results and as such is deemed to be the optimum solution. The obtained results of the validation process are presented and discussed. The change in bus voltage profile, active losses and reactive losses after connecting tie lines 37, 33 and 35 is presented in Figures 6, 7 and 8 respectively.

In the base case scenario, bus number 18 observes the least voltage level at $0.88 \mathrm{pu}$. Similarly, with the reconfiguration of the system, bus 33 sees the lowest bus voltage at $0.92 \mathrm{pu}$. Reconfiguring the network led to the overall power loss to be decreased by $25.95 \%$, while the voltage drop was improved by $5.66 \%$ at maximum bus loss at bus 18 . The effectiveness of the developed model to find out the optimum network reconfiguration is thus validated. 


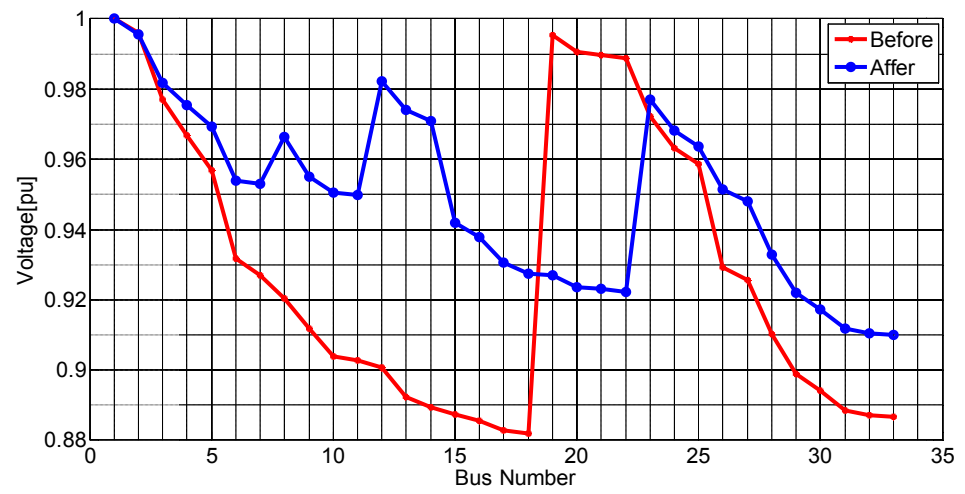

Figure 6: IEEE 33 test bus voltage profile before and after reconfiguration

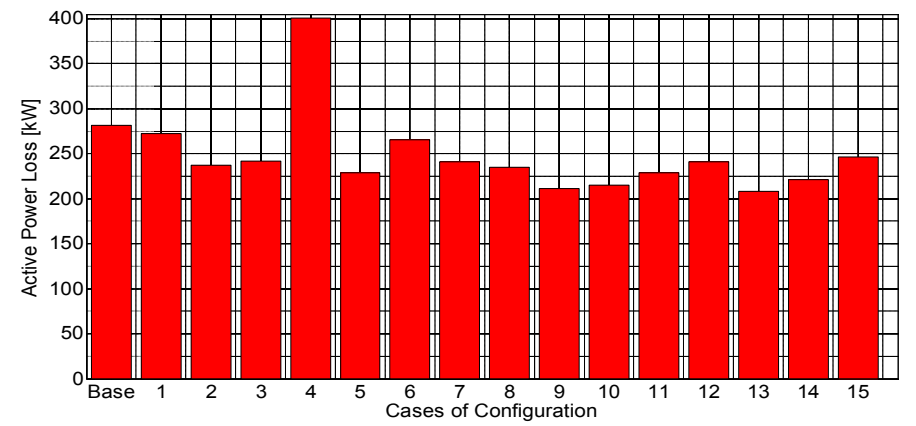

Figure 7: Active power loss of 15 reconfigure case of IEEE 33 test Bus system

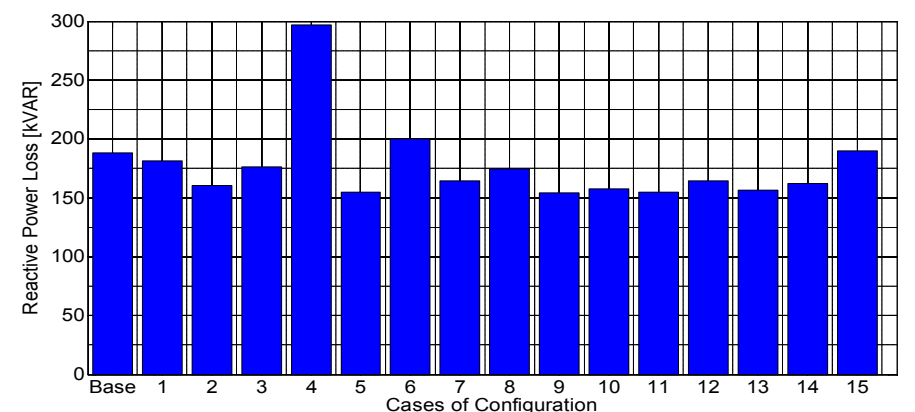

Figure 8: Reactive power loss of 15 possible reconfigurations of IEEE 33 test Bus system

\section{B. Case study of Pulchowk DCS}

As stated in Sections 2 and 3, in this study, a backward/ forward sweep algorithm-based load flow analysis is conducted at the Pulchowk DCS, which has nine radial feeders at $11 \mathrm{kV}$ voltage and 142 buses in total. Considering a fully loaded condition, the active and reactive power losses at each bus are calculated and shown in Figures 9 and 10 respectively. The minimum active power loss is observed in between the bus numbers 50 and 51 (i.e. $48 \mathrm{~W}$ ), and the maximum is observed in between the bus numbers 81 and 82 (i.e. $57.81 \mathrm{~kW}$ ). Similarly, the minimum reactive power loss is observed in between the bus numbers 50 and 51 (i.e. $0.4 \mathrm{kVAR}$ ), and the maximum in between the bus numbers 99 and 100 (i.e. $5.38 \mathrm{kVAR})$. The reactive power loss mainly depends on the bus voltage and hence their loss differs with the bus line as shown in Figure 8.

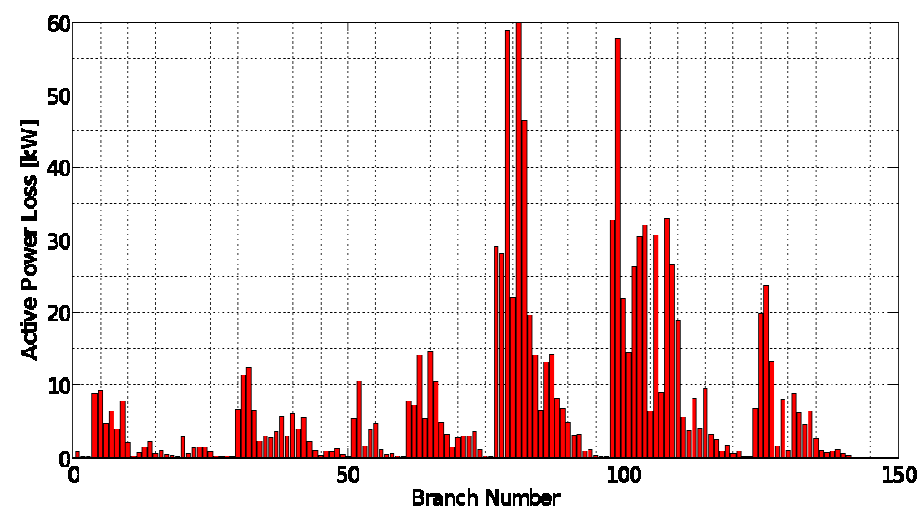

Figure 9: Active power loss of base case 142-bus Pulchowk distribution system before reconfiguration 


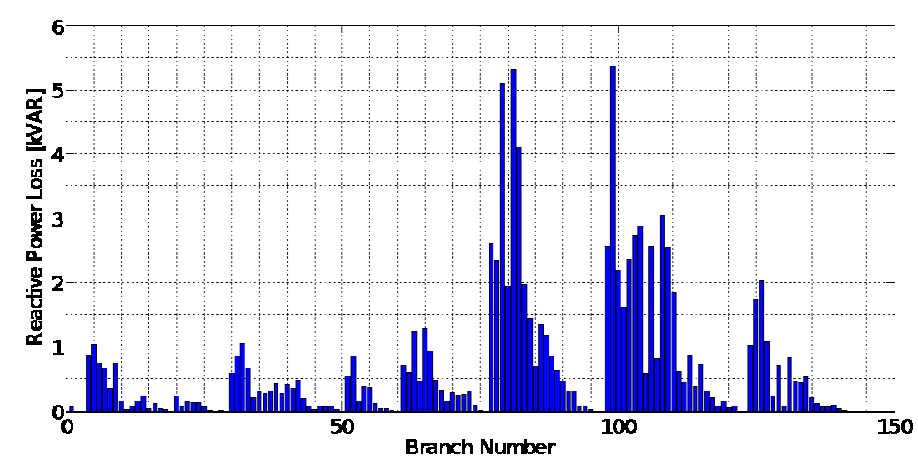

Figure 10: Reactive power loss of base case 142 bus Pulchowk distribution system before reconfiguration

From the load flow study, the total power losses are calculated to be 1,073.04 kW and $98.02 \mathrm{kVAR}$ at the base case. This calculated power loss of the existing system is high; hence reconfiguration of the network has been conducted to minimize the system losses. The reconfiguration of the system has been done based on the topological lining of feeder bus location that has been taken from GIS data of Pulchowk DCS as shown in Figure 1. Different 13 cases for possible reconfiguration have been identified and listed in Table 3 below. The total active and reactive power losses for all of the cases have been calculated through the developed model and listed in Table 3. As shown in Table 3, the active and reactive power losses for case 1 are higher than that of the base case.

Table 3: Pulchowk DCS network of a different set of reconfigurations of losses data

\begin{tabular}{ccc}
\hline Cases & Active Power Loss $(\mathrm{kW})$ & Reactive Power Loss (kVAR) \\
\hline Base case & 1073.04 & 98.02 \\
1 & 1119.57 & 102.89 \\
2 & 1036.29 & 95.60 \\
3 & 1007.11 & 92.18 \\
4 & 1014.82 & 92.86 \\
5 & 1027.40 & 93.98 \\
6 & 804.01 & 74.45 \\
7 & 923.84 & 84.42 \\
8 & 819.33 & 74.64 \\
9 & 625.76 & 56.96 \\
10 & 659.31 & 61.24 \\
11 & 632.92 & 57.28 \\
12 & 569.95 & 53.53 \\
13 & 597.78 & 54.36 \\
\hline
\end{tabular}

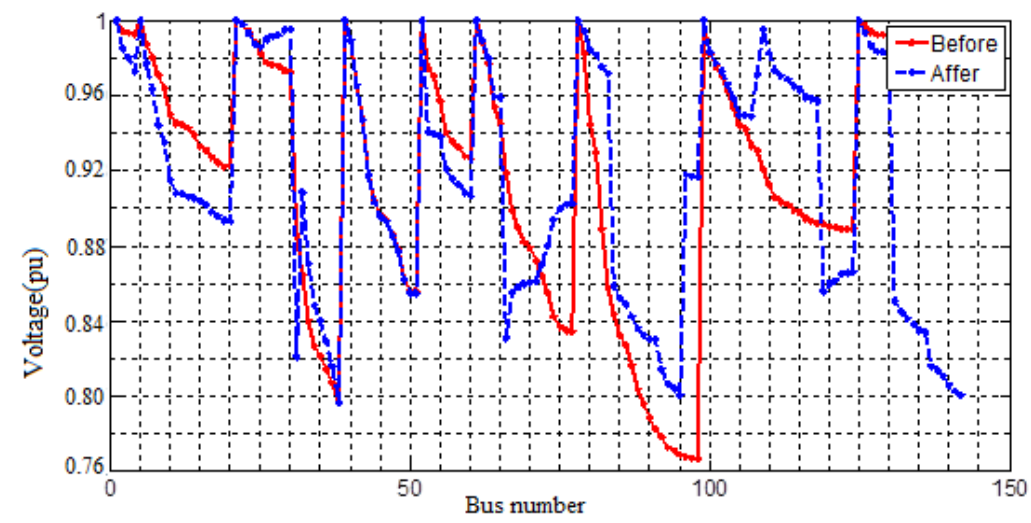

Figure 11: Graph of voltage profile of Pulchowk DCS network before and after reconfiguration

The maximum value of bus voltage is found to be $1.0 \mathrm{pu}$ at reference bus 1 , buses $5,21,39,52,61,78,99$ and 125 , and minimum bus voltage is calculated to be $0.7694 \mathrm{pu}$ at bus number 98 . The bus voltage is higher at the buses nearby reference bus, and in decreasing order with the increase of distance. Here, among all possible cases for reconfiguration of Pulchowk DSC network, the 12th case has the least losses. The reconfiguration included connecting the buses 1-16, 13-25, 12-39, 38-56, 8-66, 24-72, 38-92, 53-107, 67-119, 110-131 and 105-137. This also included opening the SESW switches between the bus sections 15-16, 24-25, 38-39, 55-56, 65-66, 71-72, 83-84, 91-92, 106-107, 118-119, 130-131 and 136-137. The changes in voltage profile after the reconfiguration of the system using the 12th case are shown in Figure 11. The overall changes in the active and reactive power losses of the system based on the 13 cases of reconfigurations are represented 
graphically in Figure number 12 and 13 respectively.

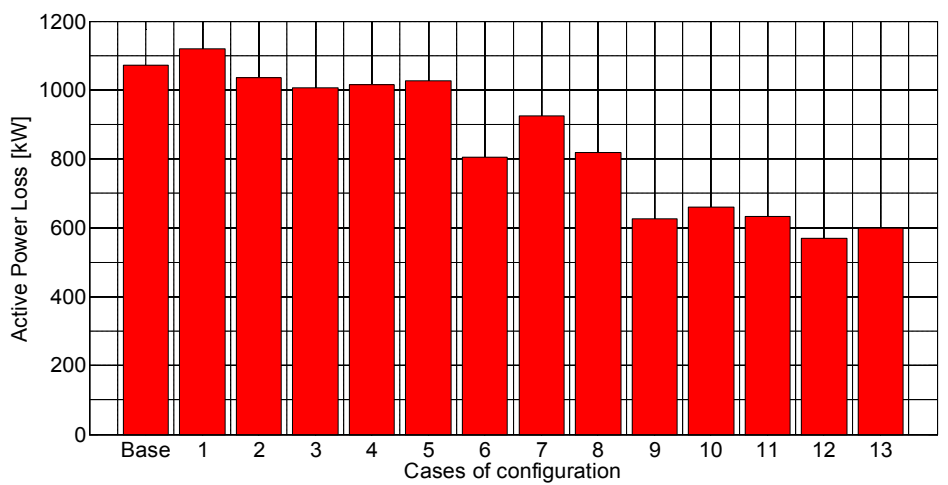

Figure 12: Graphical bar of active power loss $(\mathrm{kW})$ of Pulchowk DCS of 13 possible cases of reconfiguration

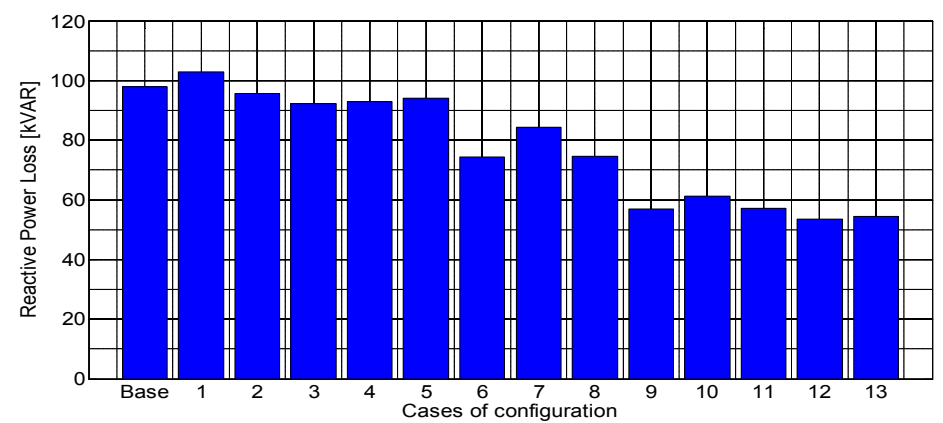

Figure 13: Graphical bar of reactive power loss (kVAR) of Pulchowk DCS of 13 possible cases of reconfiguration

From the load flow analysis, it is found that the voltage drop is reduced by $3.85 \%$ in the lowest voltage bus for the enhanced model after reconfiguration. Further, it is noted that $44.29 \%$ of active and $45.54 \%$ of reactive losses can be minimized by adopting the 12th case to reconfigure the network. That is, the total active loss is decreased from $1,073.04 \mathrm{~kW}$ to $569.95 \mathrm{~kW}$ and the reactive power loss is decreased from $98.02 \mathrm{~kW}$ to $53.53 \mathrm{kVAR}$.

\section{Conclusions}

Due to the unmanaged growth of loads in the Kathmandu valley, the losses and voltage drops in various DCS within Kathmandu have been left unchecked. Also, with the recent energy demand increase of $9.92 \%$, the overall losses and voltage drops are sure to worsen. Further, there have not been any plans to implement a planned energy demand growth within the Kathmandu valley itself nor have there been recent major works being conducted to improve and upgrade the existing distribution system in the valley. So, with no major up-gradation or construction of new infrastructure works being implemented to carter the increasing the unplanned load growth within the valley, the existing infrastructures need to be optimized as per the changing requirements.

To address these growing concerns of unplanned energy growth and lack of major up-gradation of the distribution system, reconfiguration of the existing distribution system presents a unique solution. Rather than upgrading and overhauling the entire infrastructure in place to feed the energy demand, this method reconfigures only the feeders and their connections to better optimize the load flow and decrease the overall losses while also maintaining a better voltage profile in the bus systems. This is done to figure out the extent to which the voltage profile and the losses of the system can be improved without having to perform various network up-gradation works like reconductoring the old transmission/ distribution lines, change the transformer of the distribution system, etc. After mathematical modeling of this real-world problem and developing an algorithm to find the optimum reconfiguration strategy to limit the losses, the developed solution's effectiveness has been validated using the IEEE 33 bus system. The step saw a decrease in an overall loss by $25.95 \%$, while the voltage drop was improved by $5.66 \%$ at the maximum bus loss of the system.

Finally, the analysis of Pulchowk DCS network with 9 feeders of each radial system shows that the existing system of the network has high losses and voltage drop values. In this study, an optimal configuration has been identified from all of the possible configurations. From the possible network reconfigurations, the best case is considered to be optimal concerning the percentage of reduction of power loss and voltage drop from the base case. After the re-configuration, the active and reactive power losses are found to be reduced by $44.29 \%$ and $45.54 \%$ from the base case scenario. Similarly, the voltage drop is found to be reduced by $3.85 \%$. From the results and discussions, the following conclusions were drawn,

a. With the limitation of unchanging the major infrastructure, significant improvement in the active and reactive power losses has been met. The active loss has been limited to $0.689 \%$ while the reactive loss has been limited to $0.50 \%$.

b. Improvement in the voltage profile of the system has also been achieved.

Hence, it is concluded that the optimal configurations of the distribution system can be identified by using some 
computational techniques that help to reduce the system loss and voltage drop significantly, and the existing model can be used with restructuring (reconfiguration) by allocating and re-arranging the tie-switches and sectionalizing switches. Furthermore, the simulations conducted in this study can be furthered upon addressing the following points:

a. Similar simulations can be conducted on the other DCS within the urban area to better the distribution system.

b. Selective up-gradation of the transmission/ distribution lines, transformers, etc. can be conducted to improve the voltage profile of the system further.

c. Based upon the result, a new plan for controlled energy demand increase shall be introduced to limit the system's loss and better its voltage profile.

\section{Acknowledgements}

The authors would like to thank the Department of Mechanical Engineering, Institute of Engineering, Pulchowk Campus, Tribhuvan University for their kind support during this study. The authors are also thankful to the NEA office, Pulchowk for the information sharing during this study.

\section{References}

A. V. Sudhakara Reddy, M. D. R., M. Satish Kumar Reddy. (2017). Network Reconfiguration of Distribution System for Loss Reduction Using GWO Algorithm. International Journal of Electrical and Computer Engineering, 7(6), 3226-3234.

Al-Abri, R. (2012). Voltage stability analysis with high distributed generation (DG) Penetration.

Ayodeji Olalekan Salau, Y. W. G., Dessalegn Bitew. (2020). Optimal network reconfiguration for power loss minimization and voltageprofile enhancement in distribution systems. Heliyon, 6.

Badran, O., Mekhilef, S., Mokhlis, H., \& Dahalan, W. (2017). Optimal reconfiguration of distribution system connected with distributed generations: A review of different methodologies. Renewable and Sustainable Energy Reviews, 73, 854-867.

Basiago, A. D. (1998). Economic, social, and environmental sustainability in development theory and urban planning practice. Environmentalist, 19(2), 145-161.

Flaih, F. M., Lin, X., Abd, M. K., Dawoud, S. M., Li, Z., \& Adio, O. S. (2017). A new method for distribution network reconfiguration analysis under different load demands. Energies, 10(4), 455.

Georgilakis, P. S., \& Hatziargyriou, N. D. (2015). A review of power distribution planning in the modern power systems era: Models, methods and future research. Electric Power Systems Research, 121, 89-100.

L.Ramesh, S. P. C., S.Chowdhury, A.A.Natarajan, C.T.Gaunt. (2011). Minimization of Power Loss in Distribution Networks by Different Techniques Paper presented at the International Journal of Electrical and Electronics Engineering.

Monthly loss report of Pulchowk Distribution and Consumer Services. (2019). Retrieved from Kathmandu

Napis, N. F., Khatib, T., Hassan, E. E., \& Sulaima, M. F. (2018). An improved method for reconfiguring and optimizing electrical active distribution network using evolutionary particle swarm optimization. Applied Sciences, 8(5), 804.

NEA. (2019). NEA Annual Report 2018/2019. Retrieved from Kathmandu:

Prakash, K., Lallu, A., Islam, F., \& Mamun, K. (2016). Review of power system distribution network architecture. Paper presented at the 2016 3rd Asia-Pacific World Congress on Computer Science and Engineering (APWC on CSE).

Rao, R. S., Ravindra, K., Satish, K., \& Narasimham, S. (2012). Power loss minimization in distribution system using network reconfiguration in the presence of distributed generation. IEEE transactions on power systems, 28(1), 317-325.

Shanghua Guo, J. L., Yuming Zhao, Longjun Wang, Gang Wang and Guowei Liu. (2020). A Reliability-Based Network Reconfiguration Model in Distribution System with DGs and ESSs Using Mixed-Integer Programming. energies, MDPI.

Shilpa Kalambe, G. A. (2013). Loss minimization techniques used in distribution network: bibliographical survey. Renewable and Sustainable Energy Reviews.

Shrestha, A. (2017). Planning, Design and Optimization of Distribution System for Affected Area of Upper Karnali Hydropower Project: GRIN Verlag.

Shrestha, A., Jha, S. K., Shah, B., \& Gautam, B. R. (2016). Optimal grid network for rural electrification of Upper Karnali hydro project affected area. Paper presented at the 2016 IEEE Region 10 Humanitarian Technology Conference (R10-HTC).

Shrestha, A., Kattel, R., Dachhepatic, M., Mali, B., Thapa, R., Singh, A., . . Maskey, R. K. (2019). Comparative study of different approaches for islanding detection of distributed generation systems. Applied System Innovation, $2(3), 25$.

Shrestha, A., Shah, B. B., Gautam, B. R., \& Jha, S. K. (2017). Framework development to analyze the distribution system for upper karnali hydropower project affected area. International Journal of Modern Engineering Research, 7(4), 82-91. 
Wardiah Mohd Dahalan, H. M. (2012). Network Reconfiguration for Loss Reduction with Distributed Generations Using PSO. Paper presented at the IEEE International Conference on Power and Energy.

Y. Al-Mahroqi, I. A. M., A. Al-Hinai, and A. Al-Badi (2012). Reduction of Power Losses in Distribution Systems. International Journal of Computer and Systems Engineering, 6(3). 